\title{
The calculation of temperature field in soils under the base of oilreservoiratthe Varandey oil field
}

\author{
Gennady V. Anikin ${ }^{l}$, Boris V. Grigoriev ${ }^{2,}$, KlavdiiaA. Spasennikova ${ }^{l}$, and Yulia F. \\ Yanbikova $^{2}$ \\ ${ }^{1}$ Earth Cryosphere Institute, SB RAS, 625000, Tyumen, P/O box 1230, Russia \\ ${ }^{2}$ Tyumen State University, 625003, Tyumen, Russia
}

\begin{abstract}
Temperature fields under oil reservoir at the Varandey field were calculated. Stephen's problem was considered taking into account random changes of meteorological characteristics. With the help of stochastic methods using meteorological data and technical parameters of the SDA the probability of finding soil in the unfrozen state at an arbitrary point of the computational domain has been calculated.
\end{abstract}

\section{Introduction}

The deposits of hydrocarbon and mineral resources of northern regions of Russia are of strategic importance for the country's economic stability. The intensive development of vast areas occupied by permafrost raises new issues related to the construction of engineering structures on permafrost soils in areas with harsh climatic conditions[1,2]. The districts of permafrost spread cover more than $65 \%$ of the territory of Russia, and the development of effective methods of construction under the specific conditions of these regions is of key importance.

In terms of reducing the cost of production and transportation of oil the particular importance isin building oil tanks of high-capacity near the exploited oil fields [3, 4].

This article gives a detailed transient calculation of temperature fields and the probability of the phase state of pore water in soil under the reservoir in the form of slush, in various combinations of meteorological characteristics.

The calculation is made on the example with the oil reservoir RVS - 1.4 located at the Varandey field [5]. Thermal stabilization system was put into operation in April 2006.

\section{Rated operating conditions}

The grid of spatial and temporal coordinates in the computational domain is defined by the following expressions:

$x_{i}=i \cdot h_{x}, 0 \leq i \leq 101, h_{x}=0.1 \mathrm{~m}$

$y_{j}=j \cdot h_{y}, 0 \leq j \leq 1001, h_{y}=0.1 \mathrm{~m}$

${ }^{*}$ Corresponding author: b.v.grigorev@utmn.ru 
$z_{k}=k \cdot h_{z}, 0 \leq k \leq 101, h_{z}=1 \mathrm{~m}$

$\tau_{n}=h_{\tau} \cdot n, h_{\tau}=0.01$ сут.

where $h_{x}, h_{y}, h_{z}$ - the pitch distances of coordinates $\mathrm{x}, \mathrm{y}, \mathrm{z}$, respectively, $h_{\tau}-$ the time step, $i$, $j, k$-natural numbers defining the computational grid. Thus, the computational domain is a parallelepiped with the dimensions $10 \mathrm{~m} \times 100 \mathrm{~m} \times 100 \mathrm{~m}$.

The oil reservoir in the field is a barrel having an inner diameter $d_{\text {inner }}=60.7 \mathrm{~m}$ and an outer diameter $d_{\text {outer }}=66.07 \mathrm{~m}$.Air to prevent the lateral heat flows is between the inner and the outer reservoir walls. Oil inthereservoir is at the temperature of $45{ }^{\circ} \mathrm{C}$.Under the reservoir there is a hydrophobic layer with a thickness $l_{l}=0.6$ mand thethermal conductivity $\lambda_{I}=0.95 \mathrm{~W} /\left(\mathrm{m} \cdot{ }^{\circ} \mathrm{C}\right)$, under this layer, in its turn, there is a thermal insulator layer with a thickness $l_{2}=0.4 \mathrm{~m}$ and thethermal conductivity $\lambda_{2}=0.041 \mathrm{~W} /\left(\mathrm{m} \cdot{ }^{\circ} \mathrm{C}\right)$.

The difference scheme is shownin [5-7]. The computational grid has been chosen so that the tubes of the evaporator system passed through its nodes (the tubes of evaporators are considered linear sources of cold). The interaction of the thermal stabilizer with the soil and the atmosphere was set by the following formulas $[8,9]$ :

$$
\begin{gathered}
U_{i, j, k}=\frac{\lambda_{s} h_{x} h_{z}}{h_{y}}\left(t_{i, j+1, k}+t_{i, j-1, k}-2 t_{\mathrm{T}}\right)+\frac{\lambda_{s} h_{y} h_{z}}{h_{x}}\left(t_{i+1, j, k}+t-2 t_{s t . t .}\right) \\
\sum_{i, j, k \in M} U_{i, j, k}=S_{f} \cdot \eta_{\text {eff }} \cdot\left(t_{\text {st.t. }}-t_{\text {atm }}\right) \cdot \alpha
\end{gathered}
$$

$M$-the knot set of the computational network, through which the heat stabilizer tube passes; $S_{f}$-the fins area of the heat stabilizer; $\eta_{e f f}$-the efficiency ratio of fins; $t_{s t . t}-$ the heat stabilizer temperature; $t_{a t m}$ - the atmospheric air temperature, $\alpha$-the heat transfer coefficient of condenser.

The work $\eta_{\text {eff }} \cdot \alpha$ is not known a priori. It has been determined by comparing the thermometer data with the calculated data. The best calculation agreement with the thermometry was in the following ratio: $\eta_{\text {eff }} \cdot \alpha=4,36+7,16 \mathrm{~V}$, where $\mathrm{V}$ - wind speed.

\section{Climate information about research subject}

Climate information has been used for the Varandey field. The calculation has been performed for the average monthly temperature and wind speed, the thickness of snow cover and the average power of solar radiation values calculated from the total radiation for each month in accordance with SNR 131.13330.2012, these values are shown in Table 1.

Table 1. Average values of temperature, wind speed, thickness of snow cover at theVarandey weather station, as well as the value of the average power of solar radiation measured in $\mathrm{W} / \mathrm{m}^{2}$ calculated from the total radiation for each month in accordance with SNR 131.13330.2012.

\begin{tabular}{|c|c|c|c|c|}
\hline & $\mathrm{t}_{\mathrm{a}},{ }^{\circ} \mathrm{C}$ & $\mathrm{v}, \mathrm{m} / \mathrm{s}$ & $\mathrm{h}, \mathrm{m}$ & $\begin{array}{c}\text { The average monthly output of solar } \\
\text { radiation }\left(68^{\circ} \mathrm{N}\right)\end{array}$ \\
\hline September 2007 & 6.7 & 6.4 & 0.01 & 137.5 \\
\hline October 2007 & 3.1 & 7.9 & 0.14 & 45.7 \\
\hline November 2007 & -7.7 & 6.3 & 0.21 & 12.5 \\
\hline December 2007 & -7.9 & 8.1 & 0.21 & - \\
\hline January 2008 & -9.0 & 8.2 & 0.45 & - \\
\hline February 2008 & -14.7 & 6.7 & 0.71 & 16.1 \\
\hline March 2008 & -15.4 & 7.1 & 0.79 & 219.4 \\
\hline April 2008 & -9.1 & 5.7 & 0.75 & \\
\hline
\end{tabular}


The calculation to determine the coefficient of heat transfer fins has been held from early September 2007 to the end of April 2008.

Fig. 1 shows a layout of TMD and TCB in soil. According to thermometry data there have been obtained experimental datain thermometric diameter (TMD) and the experimental data on the central thermal well (CTW).

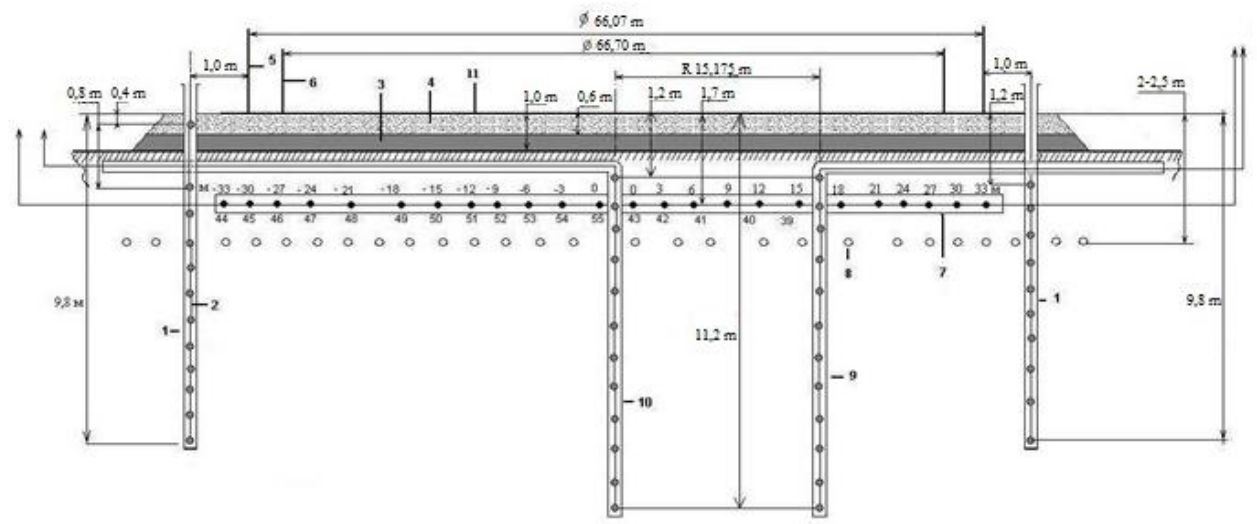

Fig. 1. Location of thermometer wells TMD and CTW under the reservoir: 1 -outside thermal wellOTW; 2 -thermistor chain TC-10;3 - insulating layer;4 -soil backfilling; 5 - protective wall; 6 -reservoir wall; 7 - thermometric diameter TMD; 8 - stabilizer of plastically frozen soils SPMG; 9 -thermistor chain (azimuth); 10 -thermistor chain inner (central) TIV; 11 -reservoir bottom.

Fig. 2 shows the comparison of theoretical calculations in the TMD and CTW carried out in the framework of this work with thermometry data. It is seen from the figures that a good agreement between theory and experiment has been achieved. Fig. 3 shows the temperature fields on 06.03.2008. under the bottom edge of penoplex at the level of the TMD and the level of pipe evaporators. It is seen from the figures that the cooling system is working properly.
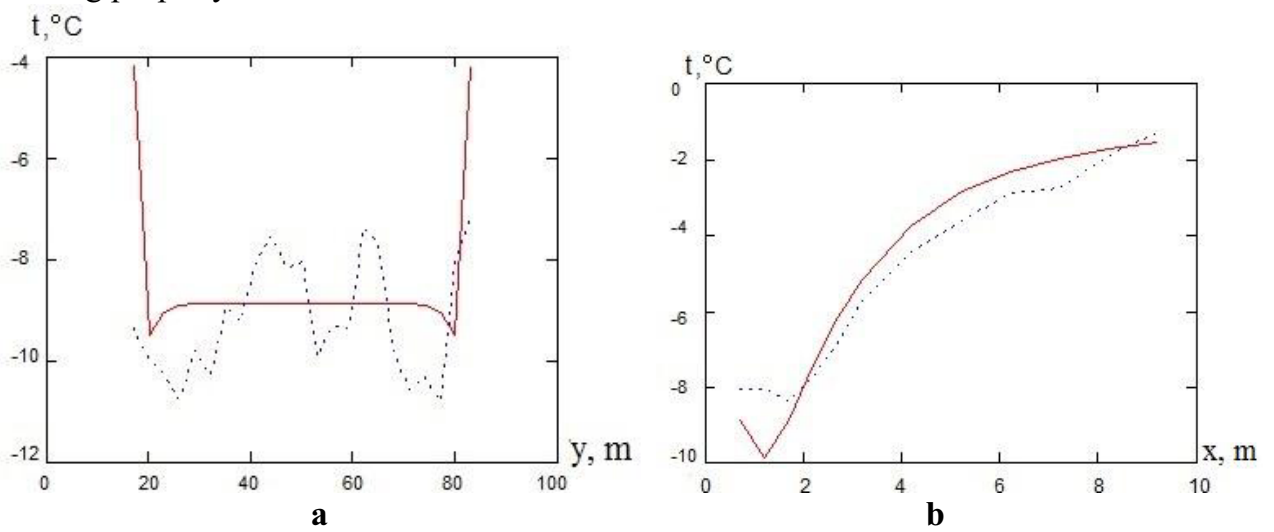

Fig. 2. Comparison of theoretical and experimental data on 06.03.08: a - in TMD; b - in CTW. The solid line - theoretical values of temperature, dashed - thermometry data. The horizontal axis is the coordinate of: $\mathrm{a}-\mathrm{y}(\mathrm{m}) ; \mathrm{b}-\mathrm{x}(\mathrm{m})$. Temperature $\left({ }^{\circ} \mathrm{C}\right)$ is plotted on the vertical axis. 


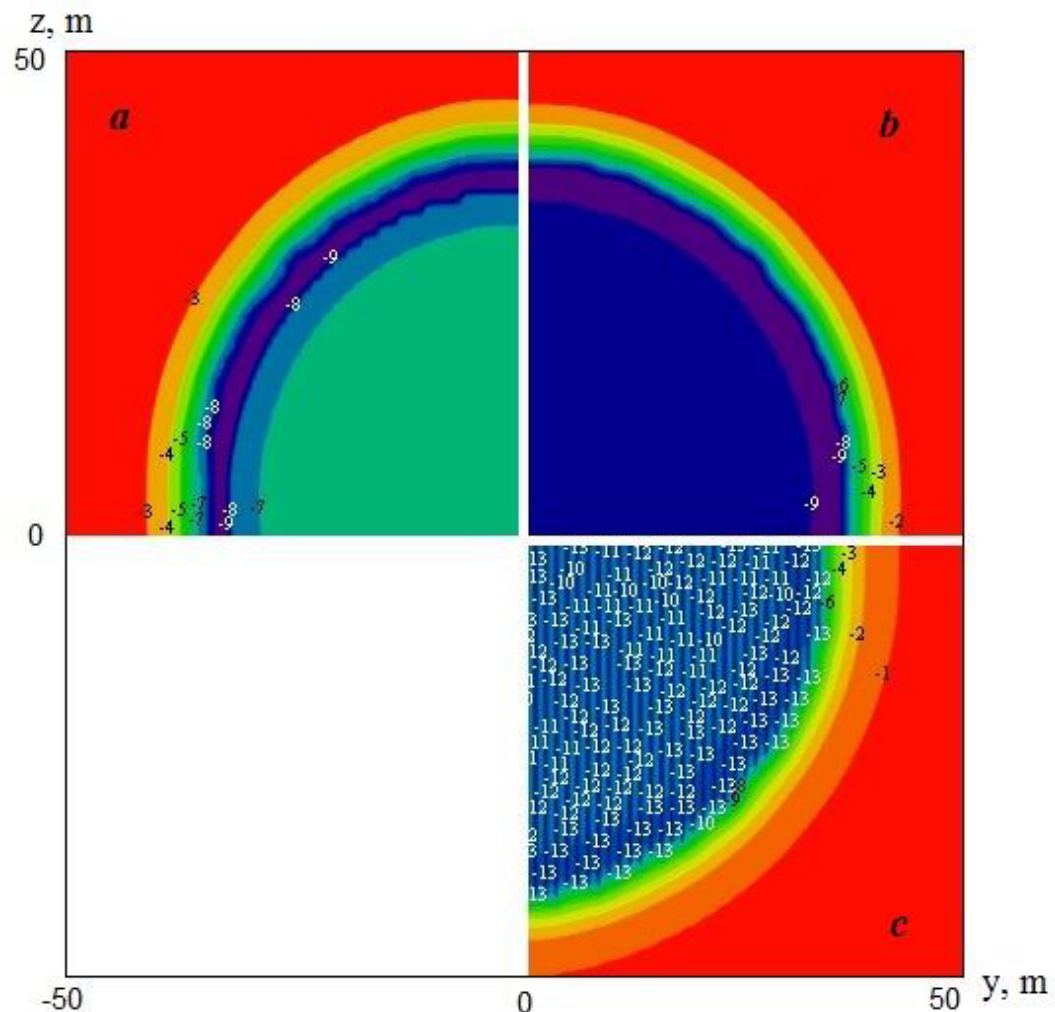

Fig. 3. The temperature field on 06.03 .08 , under the oil reservoir at the Varandey oil field: $a-$ at the level of the lower edge of penoplex; $b$ - on the TMD level; $c-$ at the level of the evaporator tubes (SPMG).

The accuracy of temperature for each thermal well is presented in Tables 2 and 3 . Where $\sigma_{\Sigma}-$ the standard deviation for each thermal well; $\sigma$-standard deviation for the sections of thermometric lateral wells TMD, where the theoretical temperature does not change; $\sigma_{e}$-the accuracy of the experimental measurements of temperature.

Table 2. The values of $\sigma, \sigma_{e}, \sigma_{\Sigma}$ for TMD on different dates in 2008 .

\begin{tabular}{|c|c|c|c|}
\hline Date & $\sigma\left({ }^{\circ} \mathrm{C}\right)$ & $\sigma_{e}\left({ }^{\circ} \mathrm{C}\right)$ & $\sigma_{\Sigma}\left({ }^{\circ} \mathrm{C}\right)$ \\
\hline 25.01. & 0.65 & 0.40 & 1.13 \\
\hline 05.02. & 0.83 & 0.40 & 1.19 \\
\hline 25.02. & 1.39 & 1.07 & 1.93 \\
\hline 06.03. & 1.06 & 1.06 & 1.62 \\
\hline 16.03. & 1.08 & 1.01 & 1.62 \\
\hline 26.03. & 0.71 & 0.70 & 1.47 \\
\hline 05.04. & 1.17 & 0.40 & 1.45 \\
\hline 18.04. & 0.61 & 1.06 & 1.09 \\
\hline 21.04. & 0.48 & 0.45 & 0.89 \\
\hline
\end{tabular}

Table 3. The values $\sigma_{\Sigma}$, forCTWon the different dates of 2008 .

\begin{tabular}{|l|c|c|c|c|c|c|c|c|c|}
\hline Date & 25.01. & 05.02. & 25.02. & 06.03. & 16.03. & 26.03. & 05.04. & 18.04. & 21.04. \\
\hline$\sigma_{\Sigma}\left({ }^{\circ} \mathrm{C}\right)$ & 0.36 & 1.03 & 1.00 & 0.70 & 0.70 & 0.93 & 1.19 & 0.65 & 0.69 \\
\hline
\end{tabular}


From the tables 2 and 3 it is seen that the standard deviation on the CTW and areas with constant temperature TMD is usually less than $1{ }^{\circ} \mathrm{C}$. In the areas of sharp changes in temperature, the standard deviation is $1.5^{\circ} \mathrm{C}$, indicating good accuracy of calculation.

Then the stochastic forecast of soil conditions in the future was held at various variants of changes in meteorological characteristics and there was determined the probability of soil in a thawed condition. According to meteorological data of theVarandeymeteorological station the probability distributions were obtained for each month based on air temperature and wind speed. The calculation formulas are given in [10]. As an illustration, Fig. 4 shows the distributions for March and September, both experimental and obtained by the random number generators of the program MathCAD-14 with the parameters set by the table 4 . The comparison shows that the probability distribution of air temperature is well described by a normal distribution, and the probability distribution of wind speed is well described by a gamma distribution [11]. For the other months, the theoretical values are also in good agreement with archival data.
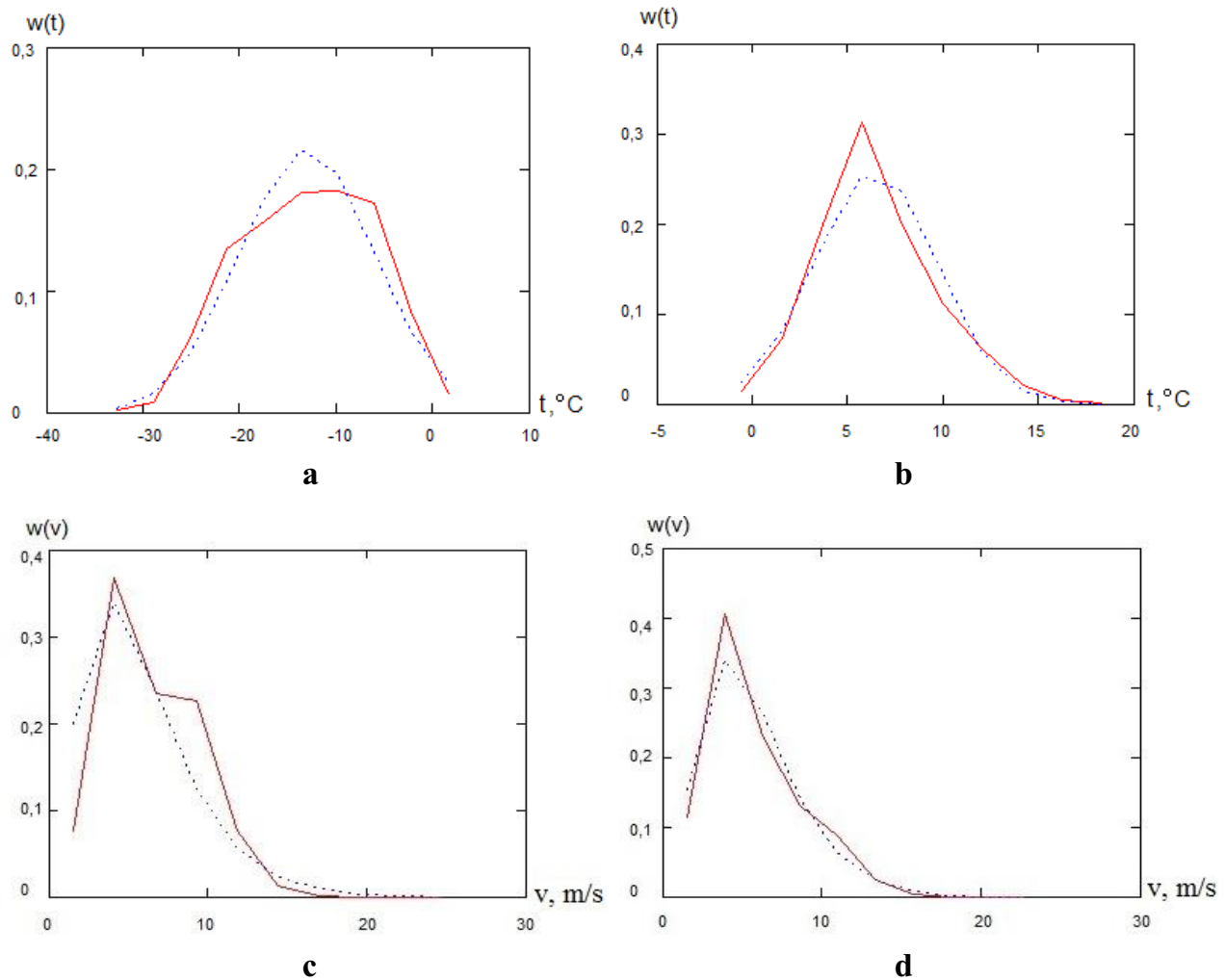

Fig. 4. The comparison of the temperature distribution $w(t)(a, b)$ and wind speed $w(v)(c, d)$ obtained from the archival data of the weather station Varandey (solid lines), with the same distributions obtained using random number generators of the program MathCAD-program 14 (dotted lines): $\mathrm{a}$ - in March; b - in September; c- in March; d- in September.

Table 4. The values obtained with archival data $\bar{t}\left({ }^{\circ} \mathrm{C}\right), \sigma\left({ }^{\circ} \mathrm{C}\right), \alpha$ and $\lambda\left(\frac{\mathrm{c}}{\mathrm{M}}\right)$ for each month.

\begin{tabular}{|c|c|c|c|c|c|c|c|c|c|c|c|c|}
\hline & Jan. & Feb. & Mar. & Apr. & May. & Jun. & Jul. & Aug. & Sep. & Oct. & Nov. & Dec. \\
\hline $\bar{t}$ & $-14,78$ & $-18,9$ & -13 & $-7,13$ & $-1,55$ & 6,07 & 10,72 & 9,16 & 6,47 & 1,53 & $-7,83$ & $-11,03$ \\
\hline$\sigma$ & 7,18 & 8,8 & 6,93 & 6,61 & 5,09 & 5,9 & 4,6 & 3,0 & 3,16 & 3,49 & 7,7 & 9,02 \\
\hline$\alpha$ & 3,04 & 3,07 & 2,73 & 3,79 & 4,0 & 3,57 & 3,86 & 4,94 & 3,4 & 5,03 & 2,73 & 4,73 \\
\hline$\lambda$ & 0,47 & 0,48 & 0,48 & 0,67 & 0,72 & 0,67 & 0,66 & 0,82 & 0,6 & 0,74 & 0,52 & 0,62 \\
\hline
\end{tabular}


Having generated $47 \times 8$ values of air temperature and wind speed for each month by using the random number generator program MathCAD-14 and using the parameters in Table 8, we get 47 options of changes over time of meteorological characteristics with the duration of 8 years each. Having begun the calculation from the beginning of September and ending in the end of August for each of the 47 scenarios, we obtain a three-dimensional temperature field for the end of August. The thickness of snow cover and the level of solar radiation are taken repeated from month to month. Having received 47 three-dimensional temperature fields at the end of August of the eighth year, we select the line, which coincides with the CVT. We calculate the temperature on this line at points with coordinates of thermometer sensors: $x=x_{j}(0 \leq j \leq 11), y=50 m, z=50 \mathrm{~m}$. The values $x_{j}$ are given in Table 5 .

Table 5. The values $x_{j}(m)$.

\begin{tabular}{|c|c|c|c|c|c|c|}
\hline$j$ & 0 & 1 & 2 & 3 & 4 & 5 \\
\hline$x_{j}$ & 0.7 & 1.2 & 1.7 & 2.2 & 2.7 & 3.2 \\
\hline$j$ & 6 & 7 & 8 & 9 & 10 & 11 \\
\hline$x_{j}$ & 4.2 & 5.2 & 6.2 & 7.2 & 8.2 & 9.2 \\
\hline
\end{tabular}

We also calculate the temperature on the line, which coincides with the TMD at the points with the coordinates of thermometer sensors. The values are given in Table 6 .

Table 6. The values $y_{i}(m)$.

\begin{tabular}{|c|c|c|c|c|c|c|}
\hline$i$ & 0 & 1 & 2 & 3 & 4 & 5 \\
\hline$y_{i}$ & 17 & 20 & 23 & 26 & 29 & 32 \\
\hline$i$ & 6 & 7 & 8 & 9 & 10 & 11 \\
\hline$y_{i}$ & 35 & 38 & 41 & 44 & 47 & 50 \\
\hline$i$ & 12 & 13 & 14 & 15 & 16 & 17 \\
\hline$y_{i}$ & 53 & 56 & 59 & 62 & 65 & 68 \\
\hline$i$ & 18 & 19 & 20 & 21 & 22 & - \\
\hline$y_{i}$ & 71 & 74 & 77 & 80 & 83 & - \\
\hline
\end{tabular}

We now estimate the probability of finding soilinthethawed state on the lines of CTW and the TMD line. For evaluation, we assume that the temperature distribution in soil in each spatial point is Gaussian distribution. Based on this hypothesis, the probability to find the temperature that is more than $0^{\circ} \mathrm{Cat}$ the point numbered $j$ onCTW line is given by the following expression:

$$
W c_{j}=100 \% \cdot \int_{0}^{\infty} \frac{\exp \left(-\left(t-\overline{t c}_{j}\right)^{2} / 2 \overline{\sigma c}_{j}^{2}\right)}{\overline{\sigma c}_{j} \sqrt{2 \pi}} d t
$$

where $\overline{t c}_{j}$-mathematical expectation of temperature at the number jon the $\mathrm{CTW}$, line $\overline{\sigma c}_{j}-$ the standard deviation of temperature at the point with the number jon the CTW line.

The probability to find the temperature that is more than $0^{\circ} \mathrm{Con}$ TMD line, in turn, is given by the following formula:

$$
W m_{i}=100 \% \cdot \int_{0}^{\infty} \frac{\exp \left(-\left(t-\overline{t m}_{i}\right)^{2} / 2 \overline{\sigma m}_{i}^{2}\right)}{\overline{\sigma m}_{i} \sqrt{2 \pi}} d t
$$

where $\overline{t m}_{i}$-mathematical expectation of temperature at the point with the number $i$ on the TMD line, $\overline{\sigma m}_{i}-$ the standard deviation of temperature at the point with the number $i$ on the TMD line. 
Here both probabilities are expressed in percentages.

Carrying out the calculations by formulas (3) and (4), we obtain Table 7 for $W c_{j}$ and Table 8 for $W m_{i}$.

Table 7.The values of the probability to find soil in the thawed condition in the end of August, the eighth calculated year atCTW line (\%).

\begin{tabular}{|c|c|c|c|c|c|c|}
\hline$j$ & 0 & 1 & 2 & 3 & 4 & 5 \\
\hline$W c_{j}(\%)$ & 3.9 & 1.2 & 0.44 & 0.16 & 0.06 & 0.02 \\
\hline$j$ & 6 & 7 & 8 & 9 & 10 & 11 \\
\hline$W c_{j}(\%)$ & 0.002 & 0 & 0 & 0 & 0 & 0 \\
\hline
\end{tabular}

Table 8.The values of the probability to find soil in the thawed condition in the end of August, the eighth calculated year at TMD line (\%).

\begin{tabular}{|c|c|c|c|c|c|c|}
\hline$i$ & 0 & 1 & 2 & 3 & 4 & 5 \\
\hline$W m_{i}(\%)$ & 98.8 & 0.27 & 3.1 & 3.9 & 4.1 & 4.1 \\
\hline$i$ & 6 & 7 & 8 & 9 & 10 & 11 \\
\hline$W m_{i}(\%)$ & 4.2 & 4.2 & 4.2 & 4.2 & 4.2 & 4.2 \\
\hline$i$ & 12 & 13 & 14 & 15 & 16 & 17 \\
\hline$W m_{i}(\%)$ & 4.2 & 4.2 & 4.2 & 4.2 & 4.2 & 4.1 \\
\hline$i$ & 18 & 19 & 20 & 21 & 22 & - \\
\hline$W m_{i}(\%)$ & 4.1 & 3.9 & 3.1 & 0.27 & 98.8 & - \\
\hline
\end{tabular}

The tables show that at a depth of $0.7 \mathrm{~m}$, where there is TMD, the probability to find soil in the thawed conditionis about four per cent that indicates the reliability of the cooling system. The dependence of soil temperature atCTW line on the coordinate $x$ for each of the three options, as well as the dependence on the temperature coordinate averaged over all variants of the futureis shown in Fig. 5a. The dependence of soil temperature at the TMD line on the coordinatey for each of the three options as well as the dependence on the temperature coordinate averaged over all options for the futureis shown in Fig. 5b.

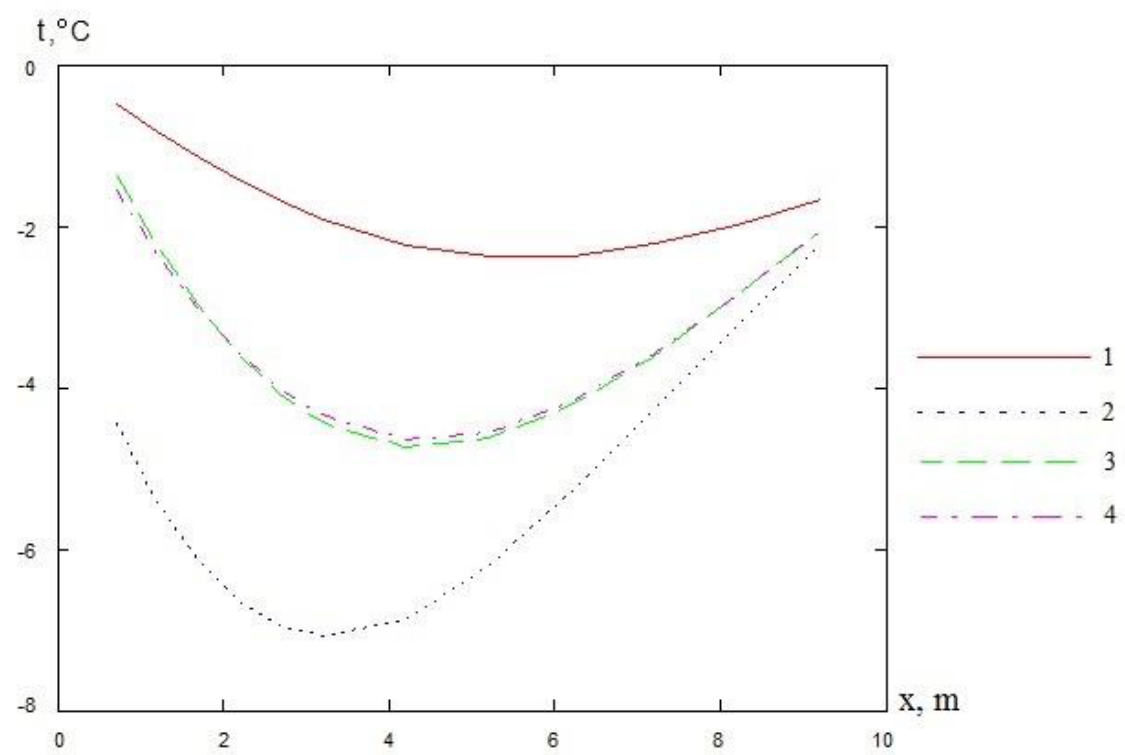

a) 


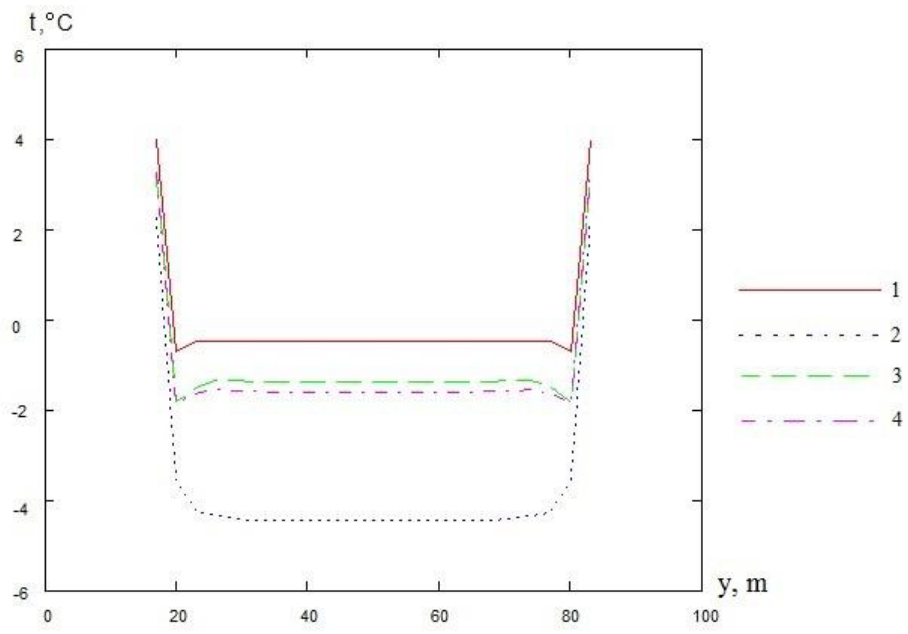

b)

Fig. 5. a) , b) The dependence of soil temperature at the end of August, the eighth calculated year: a at CTW line on the coordinate $x$, thecoordinate $x(\mathrm{~m})$ is on the horizontal axis; $\mathrm{b}$-atTMD line on the coordinate $y$, the coordinate $y(\mathrm{~m})$ is on the horizontal axis. On the vertical axis there is temperature $\left({ }^{\circ}\right.$ C). 1 - the warmest option; 2 - the coolest option; 3 - the option closest to the average one, over all the options; 4 - temperature, averaged over all variants.

It should be noted that the temperature averaged over all future options is not a solution of Stefan's problem, while the option closest to this average temperatureis such a decision [12-15]. From the figures $5 \mathrm{a}$ and $5 \mathrm{~b}$ it can be seen that the variant closest to the average is identical to this average one, so it can be considered a variant average for the sample of random trajectories.

The temperature fields in the plane given by the equation $y=50 \mathrm{~m}$ for each of the options considered are shown in Fig.6.

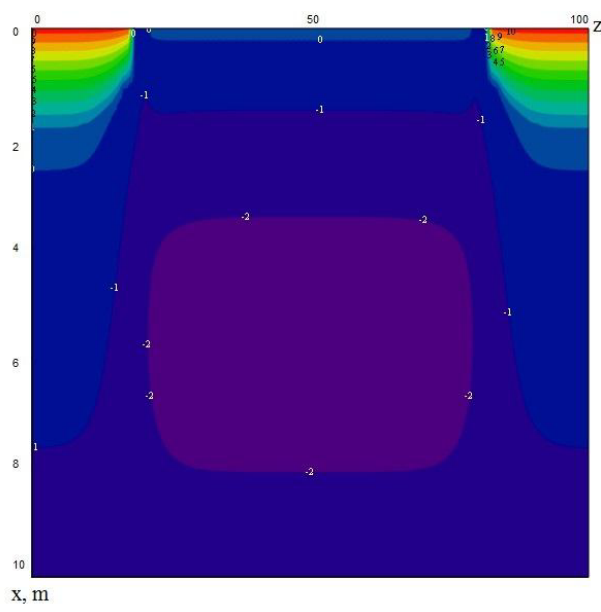

a

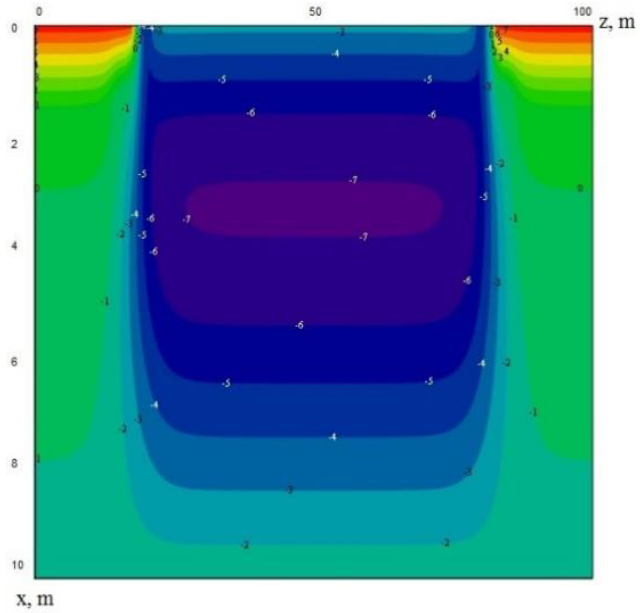

b 


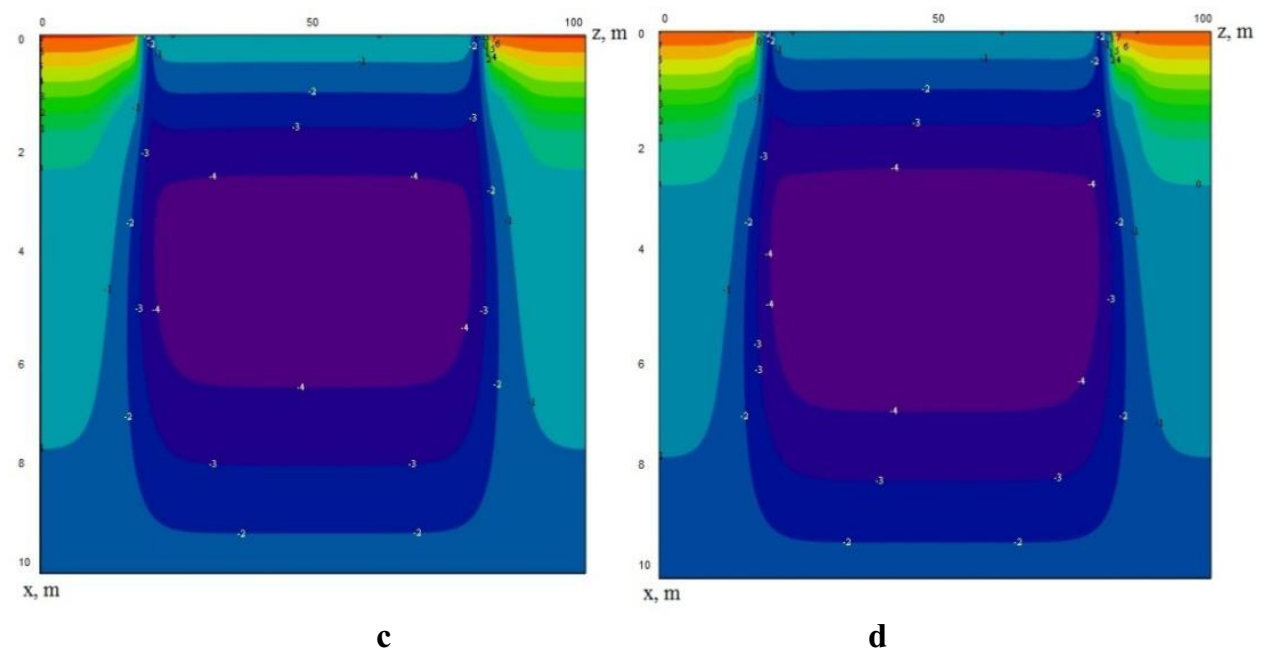

Fig. 6. The temperature field at the end of August, the eighth calculated year for the option in the plane defined by the equation $y=50 \mathrm{~m}$ (the plane passes through the center of the reservoir parallel to the tubes of the cooling system): $\mathrm{a}$-the warmest; $\mathrm{b}$ - the coldest; $\mathrm{c}$ - the most approximate to the average one over random trajectories atCTW line; $\mathrm{d}$-the closest to the average over random trajectories at the TMD line.

\section{Conclusion}

The developed method of calculating the operation of cooling systems has been confirmed in the comparison of experimental and theoretical data. Therefore, it is suitable to describe the heat transfer processes in the soils cooled by such systems.

The stochastic prediction method, in contrast to the standard method, allows making the test of the reliability of cooling systems, to explore all possible scenarios in the future and calculate at each point the probability to find the soil in thawed state. This in turn has a very great practical importance in the design of cooling systems soil.

Indeed, if this probability is tens of percent, the project should increase the number of cooling elements, if this probability is of a few percent in the order, the cooling system is optimal, but if it is fractions of a percent of the order, the number of cooling elements is excessive and the cost of the cooling system is overstated.

\section{References}

1. E. G. Starostin, Kriosfera Zemli, № 2 (In Russ.), 104, 60 (2008)

2. V. P. Ananev, A. D. Potapov, Inzhenernaya geologiya (In Russ.) (2002)

3. N. N. Karnauhov, S. Y. Kushnir, A. S. Gorelov, Mehanika merzlyih gruntov $i$ printsipyi stroitelstva neftegazovyih ob'ektov v usloviyah Severa (In Russ.) (2008)

4. Y. Shubina, Konferentsia molodyh uchenyh i specialistov posvyashchennaya XX-letiyu sozdaniya ooo npo "fundamentstroyarkos" "strategiya innovatsionnogo razvitiya stroitel'stva i osvoeniya rayonov kraynego severa (InRuss.) 274, 69 (2011)

5. G. V. Anikin, K. A. Spasennikova, Kriosfera Zemli (In Russ.), 98, 60 (2012)

6. G. V. Anikin, S. N. Plotnikov, A. A. Vakulin, K. A. Spasennikova, Vestnik Tyumenskogo gosudarstvennogo universiteta (In Russ.), 216, 46 (2013)

7. G. M. Dolgikh, S. N. Okunev, K. V. Zaleski, Kriosfera Zemli (In Russ.), 109, 65 (2014) 
8. K. A. Spasennikova, PhD Thesis (In Russ.), 154 (2015)

9. V. G. Korneev, Parallel'noe programmirovanie v MPI (InRuss.), 215 (2002)

10. G. M. Dolgikh, G. V. Anikin, I. P. Rilo, K. A. Spasennikova, Kriosfera Zemli (In Russ.), 121, 70 (2015)

11. V. P. Melnikov, A. A. Melnikova, Kriosfera Zemli (In Russ.), 113, 82 (2014)

12. L. N. Khrustalyov, I. V. Davidova, Kriosfera Zemli (In Russ.) 91, 68 (2007)

13. G. M. Dolgikh, S. N. Okunev, L. S. Podenko, V. N. Feklistov, Materialy mezhdunarodnoy konferentsii "Kriogennye resursy polyarnyh i gornyh regionov sostoyanie i perspektivy inzhenernogo merzlotovedeniya" (In Russ.), 202, 31 (2008)

14. Samarskiy, P. N. Vabishchevich, Vychislitelnaya teploperedacha (In Russ.), 728 (2003)

15. V. V. Klimenko, L. N. Khrustalev, O. V. Mikushina, L. V. Emelyanova, E. D. Ershov, S. Yu. Parmuzin, A. G. Tereshin, Kriosfera Zemli (InRuss.), 84, 3 (2007) 